\title{
Tomasz Bajkowski, U źródeł tożsamości rodzinnej. System rodzinny w percepcji młodzieży akademickiej [At the Source of Family Identity: The Family System in the Perception of the Academic Youth], Wydawnictwo Naukowe SCHOLAR, Warszawa 2018, pp. 395
}

The Author of the reviewed monograph is a graduate of the Faculty of Pedagogy and Psychology of the University of Białystok. In 2007, he obtained a PhD degree in pedagogy. His doctoral dissertation Kobiecość i męskość w percepcji współczesnej młodzieży akademickiej [Femininity and Masculinity in the Perception of Contemporary Academic Youth], as well as the book subject to this review, are the result of many years of systematic research, including aspects of diagnosis of various educational environments, models of intervention addressed to children, adolescents, adults, entire families, and identity processes, taking into account different socio-cultural contexts.

The publication of Tomasz Bajkowski, U źródeł tożsamości rodzinnej. System rodzinny w percepcji młodzieży akademickiej [At the Source of Family Identity: The Family System in the Perception of the Academic Youth], both in the theoretical layer and in the presented research procedure, is part of a wide area of interdisciplinary interest in contemporary family, using the legacy of various scientific disciplines: pedagogy, psychology, sociology, anthropology, medicine, economics, and others. However, for the dominant perspective of constructing the theoretical framework of the research project, the Author adopted the assumptions of social pedagogy showing at the same time the inspirations coming from his own experi-

Faculty of Education, University of Białystok, Poland.

E-MAIL: a.solbut@uwb.edu.pl ORCID: 0000-0003-4345-198X 
ence in therapeutic work. Tomasz Bajkowski has been working as a diagnostician and psychotherapist for over 20 years at the Private Pedagogical and Psychological Clinic "Pociecha" in Białystok.

The reviewed monograph consists of seven chapters containing theoretical, methodological and empirical parts, as well as the Introduction, Conclusions, and Diagnostic and Methodological Recommendations. The theoretical part contains an in-depth analysis of three interrelated, within the subject of the undertaken study, own contexts: the family as a psychosocial system, youth as a social phenomenon, and sources of family identity. A significant value of the monograph is the adoption of a specific theoretical model (systemic approach) and its methodological operationalisation which allows to conduct in-depth analyses and indicate the complexity of the family system.

Currently, the situation and quality of life of a contemporary man are highly affected by multidirectional changes and transformations of socio-cultural life. Of particular importance in this context is knowing the sources of building an individual identity, and in particular, identifying the importance of the family in this complex process. The interdisciplinary character of analyses and their multi-threading arouse cognitive curiosity concerning the specificity and individual character of identity dilemmas. The importance of the family in shaping individual biographies should be emphasised. It is the environment that leaves its mark in the structure of human identity to the greatest extent. The scope and permanent nature of family influences are significant here, as the Author of the book shows. The family life cycle, relations, intergenerational transmission are important. The correct course of shaping the identity depends on the co-participation of the family. Tomasz Bajkowski, taking up such important subject, assumed that "family identity is the feeling of being Someone belonging to an important, specific family community, despite the changes that take place in us and around us” (p. 8). The Author assumes that "each element of the family system can help other elements derive from mutual resources and the dynamics of relations taking place in its space” (p. 8). The book has numerous concepts of identity. When performing the operationalisation of the concept of identity, the Author comparatively analyses psychological, sociological and pedagogical perspectives. He sees the foundations of identity concepts in psychodynamic (inter alia, Sigmund Freud), behavioural (inter alia, B. Skinner), cognitive (inter alia, A. Badura, M. Jarymowicz, J. Kozielecki) and humanistic trends (inter alia, C. Roger, G.W. Allport) (pp. 79-81). The Author also indicates how the concept of identity is explored in sociology. The reader has the opportunity to learn about theories and views including those of G. Simmel, Ch.H. Cooley, G.H. Mead, A. Kłoskowska (pp. 84-87). 
Pedagogical understanding of identity in the Author's opinion is associated with self-perception of the individual and the perception of oneself in the "reflection group”. The book presents the J. Nikitorowicz's concept of a multi-faceted and constantly emerging identity (p. 88). We get to know an interesting approach to identity, among others, as a reflective awareness, as pointed out by M. Sobecki or T. Lewowicki's theory of identity behaviours (pp. 90-91). The Author analyses subsystems of identity, i.e., personal, social and cultural identity.

Tomasz Bajkowski also presents numerous definitions and typologies of the family. Conceptualisation of the concept of family is interdisciplinary. Bajkowski systematises anthropological and sociological considerations about sources of the origin of the family category. He shows how this concept is understood in economic sciences and also in sociology, pedagogy, and psychology. From this point of view, the family is treated as a "small and primary group, the environment and the educational system, the socialisation and educational institution, and the emotional and cultural community” (p. 14). The Author presents a compendium of knowledge about types of families according to different criteria. He distinguishes families due to: the form of marriage, inheritance, residence, power in the family, the choice of partners, the number of family members, the nature of the source of living, the environment of residence, the completeness of the family and the source of children (p. 21). The approach is tabular and transparent. It characterises contemporary Polish families with regard to changes such as, inter alia, demographic problems, lifestyle changes, changes in the family life model, economic and social risks.

The Author's statements presented in the book are justified in accordance with accepted standards, in a full and unambiguous manner. The collected material is rich and exploration is multidimensional. It is not only a review but it also refers to numerous Polish and foreign studies concerning the issue of constructing family identity in the perception of young adults, at the same time providing an innovative approach to the subject.

The Author aptly selected a group of subjects. He studied students of the University of Białystok, the Białystok University of Technology, and the Medical University of Białystok. 670 people took part in the study and 633 questionnaires were analysed.

It should be emphasised that at this stage of life, young people are located between the family of origin and their own family system remaining in the sphere of plans and visions. Tomasz Bajkowski convinces the reader to the trajectory of family identity which is a kind of a bridge on the timeline (p. 8). In the family space we are dealing with memories, feelings, emotions related to members of our 
family history and we also have personal identifications, attitudes and behaviours in the context of personal patterns. As a result, a young individual gives meaning to what is important to him or her. The system of the family of origin outside the past includes the present, i.e., current relations, changes, processes. In turn, the future in the sphere of a family construct is a series of questions that a young individual poses to himself or herself.

The Author shows the youth as a social phenomenon. By creating a student portrait, in reference to the research of other authors, he wonders about the specificity of academic youth. He analyses the issue of life orientation, education, profession or the importance of building social capital. Bajkowski points to the ambiguity and multidimensionality of the term 'youth', depending on the social, psychological, economic and legal context. In understanding the differences in the recognition of this conceptual category and contexts of entering the path to adulthood, the ideas of, inter alia, J. Piaget, L. Kohlberg, M. Mead, K. Mannheim, E.H Erickson, which the Author gave an overview of, are helpful (pp. 59-65).

The subject of the research is the image of the system of the family of origin as an element of the family identity of the academic youth. The applied research procedure and its stages are fully justified by research problems and their goals (diagnosis of family systems of academic youth, knowledge of their structure, specificity of interactions occurring in them, sources shaping life attitudes of the respondents, personal and social models as well as family profiles important for the surveyed students). The research project used the method of a diagnostic survey using an extensive questionnaire. The adopted procedure made it possible to determine the existing state of affairs in the subject matter and its conditions using multi-factor analysis. The exhaustive analytical and explanatory description is the proof of professionalism of the Author's research methods.

The obtained empirical data served to describe selected models of predictors (positive and negative) of the family image of the surveyed students. The extensive spectrum and types of predictors shaping the models of satisfaction with the functioning of the family of origin, as well as its sense of functionality, speak for the importance of the systemic approach in the diagnosis of the family environment.

Considerations of the Author correlate with the research of Agnieszka CybalMichalska who indicated the relations of academic youth to a career (pp. 73-74). The two studies combined create a full spectrum of issues related to the life of academic youth.

The Author assumed that as a result of the research process, it would be possible to formulate conclusions for practitioners - diagnosticians and methodologists. 
Diagnostic recommendations have a justified practical value as a basic stage in the construction and undertaking of assistance-supportive or preventive-therapeutic activities.

The Author emphasises that regularities revealed in the course of analyses and irregularities concerning the mechanisms occurring in the family system encourage broader research on this subject in the future. According to the systematic understanding of the family, it indicates the appropriateness of using research tools that are widely used in diagnostic and therapeutic procedures. The Author recalls the ideas of a systemic approach based on family problems (S. Minuchin, M. Bowen) (pp. 26-27). Theories of family systems refer to repeating patterns of mutual references of family members to each other which regulate behaviour, thus sustaining the system. The impact of family members on each other, the ways of their communication Bowen describes as family patterns. Each system has standards, rules, measures to maintain cohesion, as well as ways to meet the needs of individuals. In order to make a holistic diagnosis, it is worth remembering that in accordance with the systemic approach between the components of the family system, treated as a whole, interactions take place. Family members interact with each other in a circular manner which determines that a change in the unit or subsystem affects other units, subsystems and as a result the entire system is changed. It should also be borne in mind that every system has a tendency toward both change and stability.

According to Tomasz Bajkowski, in the diagnosis, apart from structured, narrative, biographical and interactive interviews, it is worth reaching for information obtained on the basis of a genogram that can be used for cognitive purposes and constitute an important element of the therapeutic strategy. It enables learning about family traditions transmitted consciously and unconsciously, conditioning the shape of the vision of the young individual's own life. As the Author emphasises, in this way we obtain a picture of family relationships, relations between parents and children, grandparents, parents-grandparents, and a number of inflammatory points existing in the family which gives a fuller view than in case of classical cause-and-effect diagnosis.

One can have expectations that the Author, taking the next steps on the path of scientific exploration, will develop the addressed subject matter into the indications and ideas directed to educators on how to work with a young individual, to support the family system and the relationship of the system with the surrounding social world. After all, education is one of the elements of social life, and the family remains the source, place and main purpose of education in accordance with the classical idea of social pedagogy. 
The publication of the Białystok pedagogue in a methodologically ordered way exhausts various questions, but reaching far, opens up other issues. Along with the advancement of empirical research, new issues emerge.

Summing up, reflections on the reviewed work refer to seeing its numerous qualities in the form of the broadness and detail of the presented research issues. The language spoken by the Author is an expression of the knowledge of the specificity of the topic, at the same time it is understandable for the reader who is not involved in pedagogical and therapeutic activities.

The monograph is a valuable and extremely interesting reading for many groups of recipients - both for students and practitioners, as well as for people who scientifically study family life. 